\title{
CLASSIFICATION OF MAGNETOSPHERIC RESPONSES TO INTERACTION WITH DIAMAGNETIC STRUCTURES OF SLOW SOLAR WIND
}

\author{
V.A. Parkhomov \\ Baikal State University, \\ Irkutsk, Russia,pekines_41@mail.ru \\ V.G. Eselevich \\ Institute of Solar-Terrestrial Physics SB RAS, \\ Irkutsk, Russia,esel@iszf.irk.ru \\ M.V. Eselevich \\ Institute of Solar-Terrestrial Physics SB RAS, \\ Irkutsk,Russia,mesel@iszf.irk.ru
}

\section{A.V. Dmitriev}

Lomonosov Moscow State University,

Skobeltsyn Institute of Nuclear Physics

Moscow,Russia,dalexav@mail.ru

\author{
A.V. Suvorova \\ Lomonosov Moscow State University, \\ Skobeltsyn Institute of Nuclear Physics \\ Moscow, Russia,alla_suvorova@mail.ru \\ T.I. Vedernikova \\ Baikal State University, \\ Irkutsk,Russia,vedernikovati@bgu.ru
}

\begin{abstract}
We propose a possible classification of the responses of the magnetosphere to the interaction with diamagnetic structures (DS), which form the basis of the slow solar wind. The main determinants of the classification are the value and orientation of the vertical component $B_{z}$ of the interplanetary magnetic field (IMF) and the solar wind density N. We have identified three types of magnetospheric responses. Type 1 has two subtypes whose main difference is the presence or absence of auroras on the day side of the magnetosphere. Within an hour before DS arrival, $B_{z}$ has a positive value (up to $12 \mathrm{nT}$ ) or fluctuates about 0 in the range from -1 to $+1 \mathrm{nT}$. For both subtypes, the duration of substorm disturbances approximately coincides with the duration of DS, and their intensity does not
\end{abstract}

exceed $A E \sim 500 \mathrm{nT}$. Type 2 is characterized by the fact that before the contact with DS positive IMF $B_{z}(0-10 \mathrm{nT})$ is recorded for an hour, and at the interface of DS a rapid ( $\leq 2 \mathrm{~min}$ ) change in the orientation of the IMF vertical component from north to south occurs. For type $3, B_{z}$ within an hour before the contact with DS is negative (from -10 to $0 \mathrm{nT}$ ).

We address the problem of DS energy transfer to the magnetosphere.

Keywords: slow solar wind, diamagnetic structure, classification of magnetospheric responses, substorm disturbance.

The analysis carried out in [Eselevich, Eselevich, 2005] has revealed that the higher brightness rays of streamer belts (heliospheric plasma sheet or HPS) and streamer chains that continue from the Sun to Earth's orbit are diamagnetic tubes or diamagnetic structures (DS) [Parkhomov et al., 2018], which form the basis of slow SW. In Earth's orbit, they are recorded as a sequence of DS of different scales and are determined from anticorrelation (hereinafter by anticorrelation is meant a negative correlation coefficient) between IMF modulus variations and SW density jumps. Karlson et al. [2015] observed similar structures in SW and in the transition layer of the magnetosphere and called them diamagnetic plasmoids. However, the term «diamagnetic structure» describes a much broader type of slow SW structures, and we will therefore use it in our follow-up studies.

The first attempts to study collisions of DS of slow $\mathrm{SW}$ (at $1 \mathrm{AU} V_{\max } \approx 250 \div 450 \mathrm{~km} / \mathrm{s}$ ) with Earth's magnetosphere have shown that the collisions can cause an increase in planetary geomagnetic activity, and individual DS can lead to short-term enhancements of auroral magnetic activity, which roughly coincide with the duration of the DS impact in properties similar to sawtooth substorms, but have shorter durations and lower intensi- 
ties [Parkhomov et al., 2011; Parkhomov et al., 2018].

It is important to note that the concept of sawtooth substorms, which represent strong magnetic disturbances whose intensity periodically sharply increases and decreases, has been introduced in [Huang et al., 2003, Clauer et al., 2006]. Such substorms are associated with fast SW streams $\left(V_{\max } \approx 450-800 \mathrm{~km} / \mathrm{s}\right.$ ) from coronal holes and with southward IMF for at least one hour before the interaction with the magnetosphere. The southward $B_{z}$ component may oscillate or be stable. The most powerful sawtooth substorms accompanying global magnetic storms were observed when the IMF southward component was consistently high before the beginning of the interaction with the magnetosphere. At the same time in our papers [Parkhomov et al., 2018; Parkhomov, 2019], we have shown that substorms like sawtooth substorms but with lower intensity occurred when slow SW affected the magnetosphere at both negative and positive $B_{z}$ for at least one hour before the beginning of the interaction.

The magnetospheric response is a complex of electrodynamic phenomena in the magnetosphereionosphere system, which comprises magnetic storms, magnetospheric substorms, and geomagnetic pulsations in a wide frequency range. The main characteristic of these phenomena are indices reflecting conditions of different magnetospheric regions. The most informative indices are those that measure the state of magnetosphere-ionosphere current systems. The SYMH index defines the state of the ring current from low-latitude observatories' data; $A E, A L, A U$ measure the ionospheric dynamics in ionospheric currents in the auroral zone, and the $P C N$ index indicates the current strength of the polar cap.

The purpose of this paper is to classify magnetospheric responses to the interaction with DS in slow SW. Features of these responses are better described in [Eselevich, 2019], and some their types are presented in [Parkhomov et al., 2018; Parkhomov et al., 2019].

Considering types of the responses, we refer to [McPherron et al., 2008], where it is emphasized that long-term studies on magnetospheric responses to jumps of SW and IMF parameters have identified responses of different types: substorms, pseudobeakups, Poleward Boundary Intensification (PBI) of auroral emission, Steady Magnetospheric Convection (SMC), intervals of prolonged high-intensity $A E$ activity, magnetic storms, and storm activations. Type of each response depends on the combination of parameters of outside forces and internal state of the magnetosphere.

We, therefore, use the term "substorm-like disturbance" since the term "substorm" introduced by Akasofu [Akasofu, 1964] clearly defines the sequence of physical processes in the nightside magnetosphere, including energy accumulation in the magnetotail, its explosive release, and recovery to the undisturbed level. These processes last for 1-3 hrs. The magnetospheric responses of interest have many substorm characteristics, but differ in dynamics and duration, which determines the use of the term.

\section{DATA AND METHODS}

To address the posed problem, we have used SW and IMF observations [https://cdaweb.sci.gsfc.nasa. gov/cdaweb/istp_public/], OMNI Combined, Definitive, 1-minute IMF and Plasma Data Time-Shifted to the Nose of the Earth's Bow Shock, plus Magnetic Indices. We have analyzed data for 1996-2016. We have selected 210 areas of slow SW with $V \sim 250 \div 450 \mathrm{~km} / \mathrm{s}$.

We chose the areas of slow SW that were free of interplanetary shocks $(V \sim 250 \div 450 \mathrm{~km} / \mathrm{s})$ with IMF modulus and SW density variations such that the anticorrelation coefficient varied between $r(N, B) \sim-0.6 \div-0.9$. Then, areas with high $r$ were systematized by the nature of the IMF vertical component variation at hour intervals preceding the beginning of DS. To exclude the effect of seasonal variation in the vertical component (Russell-McPherron effect) [O'Brien, McPherron, 2002], the component was considered in the solarmagnetospheric coordinate system $B_{z \mathrm{GSM}}$.

Of 360 isolated substorms [http://pgia.ru/content/ site/pages/PGI-DATA/List-substo rms_rus.pdf], we have selected the events that meet our criteria. Analyzing this list, we have found that $\sim 11 \%$ of substorms were linked to fast ( $V>450 \mathrm{~km} / \mathrm{s}$ ) SW streams, and 24 $\%$ of substorms associated with slow SW had DS.

We have identified responses of several types according to the sign and value of IMF $B_{z}$ in SW for at least one hour before the arrival of DS in Earth's orbit.

The first type: $B_{z}$ for an hour before the arrival of DS has a large positive value (to $12 \mathrm{nT}$ ) or fluctuates between $-1 \div 1 \mathrm{nT}$. The second type: for an hour prior to DS, IMF with large positive $B_{z}(0 \div 12 \mathrm{nT})$ is recorded; and on the boundary of DS, IMF rapidly (for about two minutes) changes its orientation from northward to southward. The third type: $B_{z}$ for one hour before the interaction with DS is negative $(-10 \div 0 \mathrm{nT})$.

Features of type 1 magnetospheric response to the interaction with DS. Observational results

Type 1 responses are characterized by the fact that the interaction with DS occurs against the long prior existence of predominantly northward $B_{z}$, and the onset of a substorm-like disturbance is not linked to the change in the $B_{z}$ direction. To illustrate the basic laws of the interaction of this type, we analyze an isolated magnetic bay, which occurred on December 31, 2007, from the PGI-DATA/List-substorms [Vorobjev et al., 2018] (Figure 1).

This interval refers to the structure of the slow solar wind, and its source on the Sun is a streamer chain. The procedure for identifying the solar source is described in [Parkhomov et al., 2019] and is shown below for another event. From top to bottom are IMF modulus $B$, SW plasma density $N_{\mathrm{SW}}$, IMF $B_{z}, V_{\mathrm{SW}}$, pressure $P$, SW electric field $E_{l}$, distance to the bow shock wave $R_{\mathrm{e}}$ at $1 \mathrm{AU}$, indices of auroral magnetic and geomagnetic activities $A E, A L, S Y M H$, and $P C N$, derived from OMNI data [http://cdaweb.gsfc. nasa.gov/cgi-bin/eval2.cgi]. The rectangle marks DS; inside is the correlation coefficient between $B$ and $N(r=-$ $0.94)$. The thin rectangle indicates the interval corresponding to the maximum development of the substorm. 


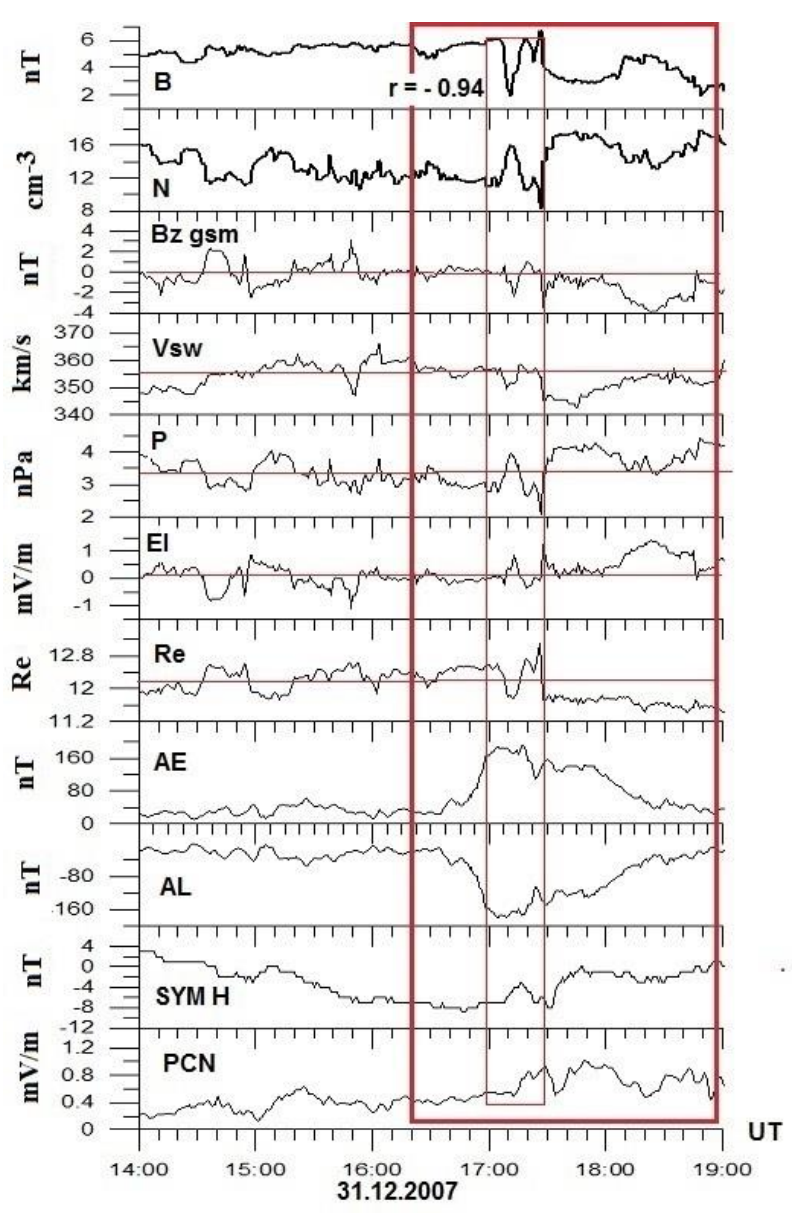

Figure 1. A magnetospheric response to the interaction with the diamagnetic structure of the slow solar wind on December 31,2007 . The red rectangle is the interval of the interaction; the thin rectangle marks the interval corresponding to the maximum development of the disturbance

Consider the details of the interaction that occurs at a low level of magnetic activity $\left(K_{\mathrm{p}}=1+\right) ; S Y M H$ varies between $-3.5 \pm \pm 3.5 \mathrm{nT}$ for two hours before the onset of the event. The average value of $P C N$ determined from the SW electric field [Troshichev et al., 2006] remains low, $0.38 \pm 0.01 \mathrm{mV} / \mathrm{km}$, which does not correspond to the level of onset of the substorm. The IMF vertical component $B_{z}$ fluctuates around zero with a mean value of $B_{z \mathrm{GSM}}=-0.031 \pm 0.04 \mathrm{nT}$. Thus, for the previous two hours conditions in SW do not correspond to the mode of pumping of energy into the magnetosphere. Nonetheless, at 16:40 UT a weak isolated substorm with maximum $A E=190 \mathrm{nT}(A L=-179 \mathrm{nT})$ begins. The onset and duration of the substorm concur with the interaction between DS and the magnetosphere, and the substorm reaches its maximum intensity at maximum deviations of $B$ and $N$ from their mean values before the disturbance (marked with a thin rectangle).

Figure 2 shows a sequence of images of the south polar auroral oval. We can clearly see the evolution of the substorm in auroras: the initial brightening at $16: 40: 44$, the local breakup at $16: 51: 47$, the maximum at 17:20:15, and the end at 18:32:22 UT. The picture of the evolution in auroras coincides with $A E$ and $A L$ variations and leads to the confident conclusion that DS has become an energy source of the isolated substorm con- sidered. This statement is also argued by the absence of the growth phase linked to the long-lived southward $B_{z}$, the prolonged absence of dynamic pressure $P$ jumps in SW, interplanetary electric field $E_{l}$, and hence by low $P C N$. The duration of the substorm coincides with the duration of DS.

Estimate the energy DS contributes to the magnetosphere and compare it with the possible energy release during the substorm for the interval indicated by the thin rectangle.

Estimated $E_{\text {kin }}$ for the December 31, 2007 event for DS between 17:00 and 17:30 UT

Take mean SW parameters for the interval $\Delta t \approx 30$ $\min =1800 \mathrm{~s}$ roughly equal to the duration of DS and indicated by the thin rectangle in Figure $1: N \approx 14 \mathrm{~cm}^{-3}$; $V_{\mathrm{SW}} \approx \approx 355 \mathrm{~km} / \mathrm{s}$; the DS diameter $d \approx \Delta t V_{\mathrm{SW}} \approx 1800$ $\cdot 355 \approx 6.4 \cdot 10^{5} \mathrm{~km}$; the DS cross-section area $S \approx \pi d^{2} / 4 \approx$ $3.3 \cdot 10^{11} \mathrm{~km}^{2}$; the length of DS affecting the magnetosphere $L \approx 30 R_{\mathrm{e}} \approx 1.9 \cdot 10^{5} \mathrm{~km}$; the DS volume $v \approx L S \approx$ $6.3 \cdot 10^{31} \mathrm{~cm}^{3} ; V_{\mathrm{SW}}{ }^{2} \approx 1.3 \cdot 10^{15}(\mathrm{~km} / \mathrm{s})^{2} ; E_{\mathrm{kin}}=N v m_{\mathrm{p}} V_{\mathrm{SW}}{ }^{2} \approx$ $9.4 \cdot 10^{23} \mathrm{erg}=9.4 \cdot 10^{13} \mathrm{~J}$.

Compare them with the substorm energy release estimated by Akasofu [Akasofu, 1980]. According to his calculations, at the beginning of a substorm $\varepsilon / t \approx 10^{18} \mathrm{erg} / \mathrm{s}$ is released, while during a typical substorm $10^{18} \mathrm{erg} / \mathrm{s}<<$ $<<\varepsilon / t<10^{19} \mathrm{erg} / \mathrm{s}$ is released.

If the typical substorm duration is $\sim 60 \mathrm{~min}$, the total energy may be $5 \cdot 10^{21} \mathrm{erg}<\varepsilon<<5 \cdot 10^{22} \mathrm{erg}$.

For different substorms other estimated energy releases for $90-\min (E(90))$ substorm duration are available on the website [http://space-weather.ru/ru/node/32] of IKI RAS "Short-Term Forecast of Space Weather": for quiet conditions $E(90)<10^{14} \mathrm{~J}$; for weak substorms $E(90)=10^{14}-10^{15} \mathrm{~J}$; for strong substorms $E(90)=10^{15}$ $5 \cdot 10^{15} \mathrm{~J}$; for very strong substorms during a storm $E(90)>5 \cdot 10^{15} \mathrm{~J}$.

If we consider that our calculation is made for a 30 min disturbance, we can see good agreement with the estimates presented on this website.

Thus, observation of the magnetospheric response to the slow SW DS effect as a weak isolated substorm and estimation of the DS kinetic energy show that the interaction between DS of this type and the magnetosphere may initiate a substorm-like disturbance (isolated substorm), during which such an amount of energy is released that is comparable to the energy of a weak substorm, accumulated in the magnetotail due to reconnection. Here, we do not discuss the mechanism of energy transfer into the magnetosphere.

\section{Other examples of type 1 responses}

Consider some more isolated substorms and substormlike disturbances such that their onsets were preceded by the long-lived northward IMF component. Next, view critically the substorm-like events that have been studied in [Tagirov et al., 1998; Parkhomov et al., 2005; Keika et al., 2009]. Sources of these events were assumed to be dynamic pressure jumps in SW, which were caused by sharp jumps in the SW density. We examine these events as magnetospheric responses to the DS-magnetosphere interaction. The events are illustrated in Figure $3, a-c$. 


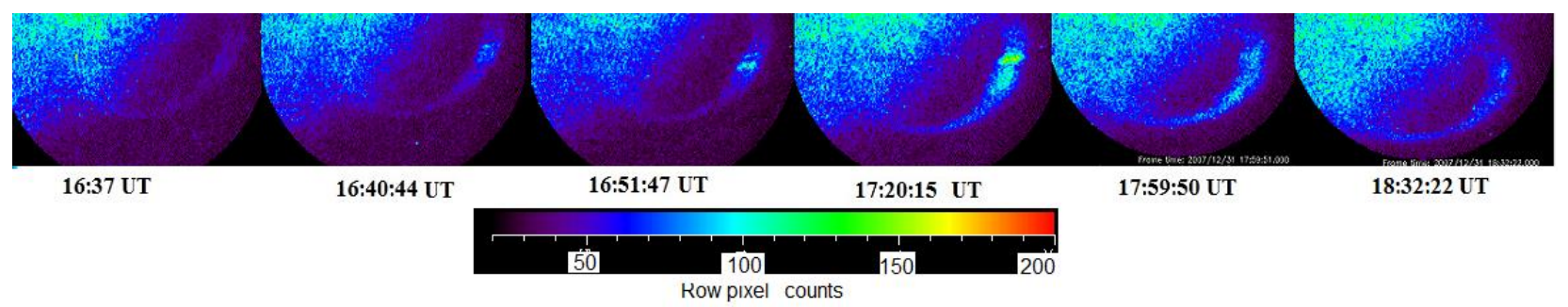

Figure 2. Sequence of images of the polar ionosphere of the Southern Hemisphere taken by the Polar satellite with the aid of the PO_LEVEL1_UVI device having the LBHL filter in the December 31, 2007 event
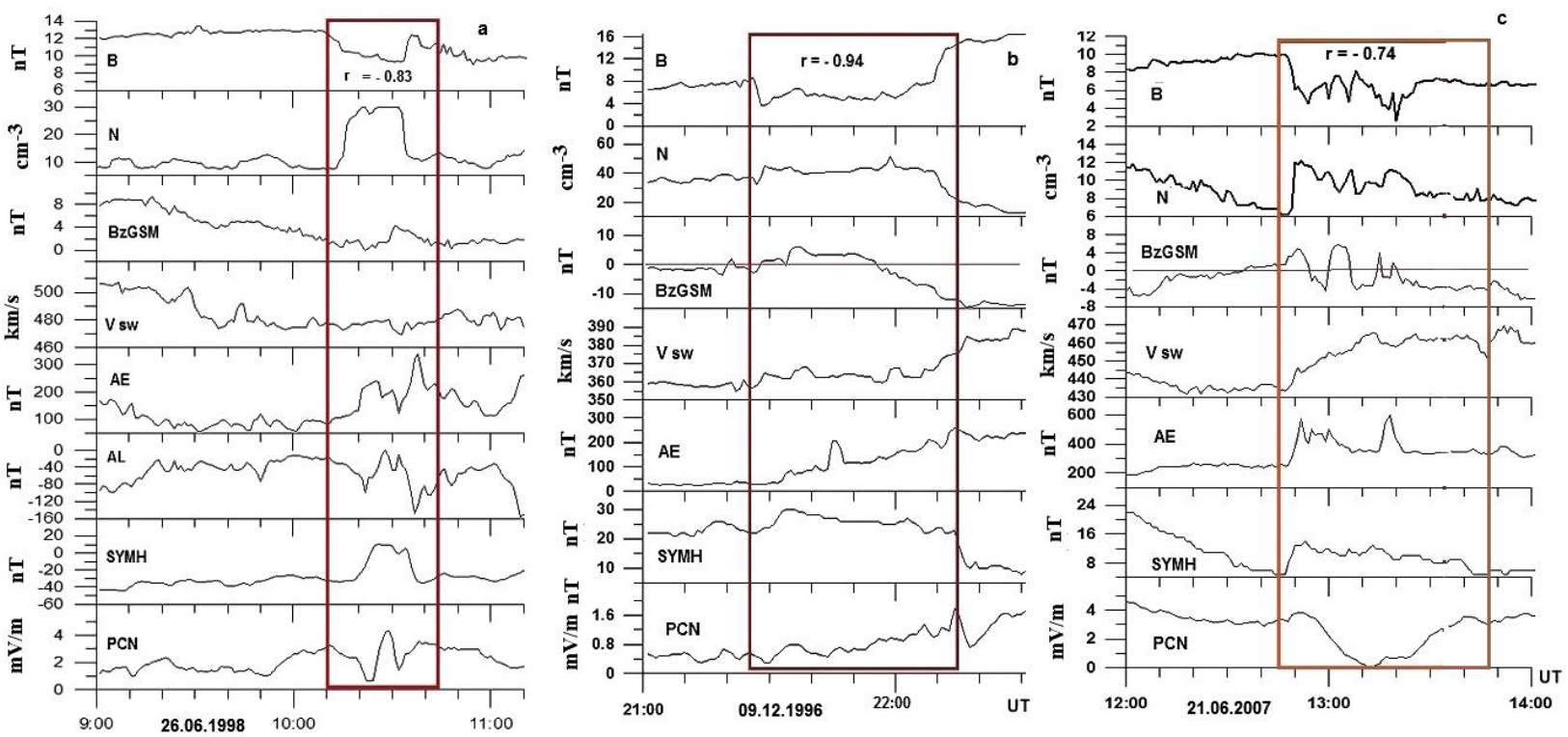

Figure 3. Examples of magnetospheric responses to the interaction with DS at preceding northward $B_{z}$ on June 26, 1998, December 09, 1996, June 21, 2007. From top to bottom: modulus of IMF $B$, SW plasma density $N$, IMF $B_{z}$ component $\left(B_{z \mathrm{GSM}}\right), V_{\mathrm{SW}}$ at $1 \mathrm{AU}, A E, S Y M H$, and $P C N$. Rectangles mark DS; inside is the correlation coefficient. According to OMNI data [http://cdaweb.gsfc.nasa.gov/cgi-bin/eval2.cgi]

Details of the substorms are given in [Parkhomov et al., 2005] (a), [Tagirov et al., 1998] (b), [Keika et al., 2009] (c). Let us consider each event in more detail.

\section{The June 26, 1998 diamagnetic structure}

That day at 10:10 UT, the Interball satellite near the magnetopause in SW recorded an abrupt increase in $N$ by $21 \mathrm{~cm}^{-3}$, a decrease in $B$ by $8 \mathrm{nT}$, and recovery to the initial level at the time interval of $\sim 20 \mathrm{~min}$. The correlation coefficient $r(N, B)=-0.83$. Such an event can therefore be interpreted as DS. It is noteworthy that $V_{\text {avSw }}=484 \pm 10.5 \mathrm{~km} / \mathrm{s}$ ) and IMF components do not experience appreciable variations $\left(B_{\mathrm{av}}=11.77 \pm 1.35\right.$ nT), and the vertical component $B_{z}$ over the interval of interest is positive, $3.9 \pm 2.67 \mathrm{nT}$ ( Figure $3, a$ ). Positions of satellites on June 26, 1998 are given in Table 1.

Table 1

\begin{tabular}{|c|c|c|c|c|}
\hline Satellite & \multirow{2}{*}{$\mathrm{UT}$} & \multicolumn{3}{|c|}{ Coordinates } \\
\cline { 3 - 5 } & & $x_{\mathrm{GSM}}, R_{\mathrm{e}}$ & $y_{\mathrm{GSM}}, R_{\mathrm{e}}$ & $z_{\mathrm{GSM}}, R_{\mathrm{e}}$ \\
\hline Interball-1 & $10: 10$ & 15.3280 & -10.9960 & -10.1860 \\
\hline WIND & $10: 10$ & 60.5 & 64.34 & -12 \\
\hline GOES 8 & $10: 10$ & -1.34424 & -6.21302 & 1.81636 \\
\hline GOES 9 & $10: 10$ & -5.81737 & -1.35223 & 2.83467 \\
\hline Polar & $10: 10$ & 3.51 & 1.86 & 6.81 \\
\hline
\end{tabular}

This event is distinctive in that there were shock-type auroras in the dayside magnetosphere after the contact with DS [Spann et al., 1998; Zhou, Tsurutani, 1999] (Figure 4), whereas at the night side there was a short-term enhancement of the westward electrojet [Parhomov et al., 2005], which started after dipolization of the geomagnetic field at the midnight side ( $B_{x}$ and $B_{z}$ in antiphase) (Figure 5,c), recorded by the geostationary satellite GOES-9, which was at the midnight side along the axis of the plasma sheet.

Intensification of auroras in the polar cap at a $70^{\circ}$ $75^{\circ}$ latitude started in the 09-12 MLT sector at 10:19:57 (Figure 4). Until 10:30 UT, auroral activity is observed in the polar cap, and then it gradually increases in the 21-0 MLT sector until $\sim 10: 45$ UT at latitudes of the auroral oval. This moment coincides with the beginning of dipolization in the plasma sheet and with the occurrence of a negative bay according to CPS observatory data (vertical line in Figure 5,c). The Polar satellite crossed the north cusp at a distance of $\sim 7 R_{\mathrm{e}}$ and $\sim 14$ MLT and, judging from the spectrum (Figure 5, $b$ ), detected a hot plasma in the magnetic layer, which appeared due to the passage of DS. Duration of the hot plasma recording (10:21-10:35 UT) roughly corresponds to the duration of DS, which might confirm the relationship between these phenomena. Coordinates of the satellites are listed in Table 1. 


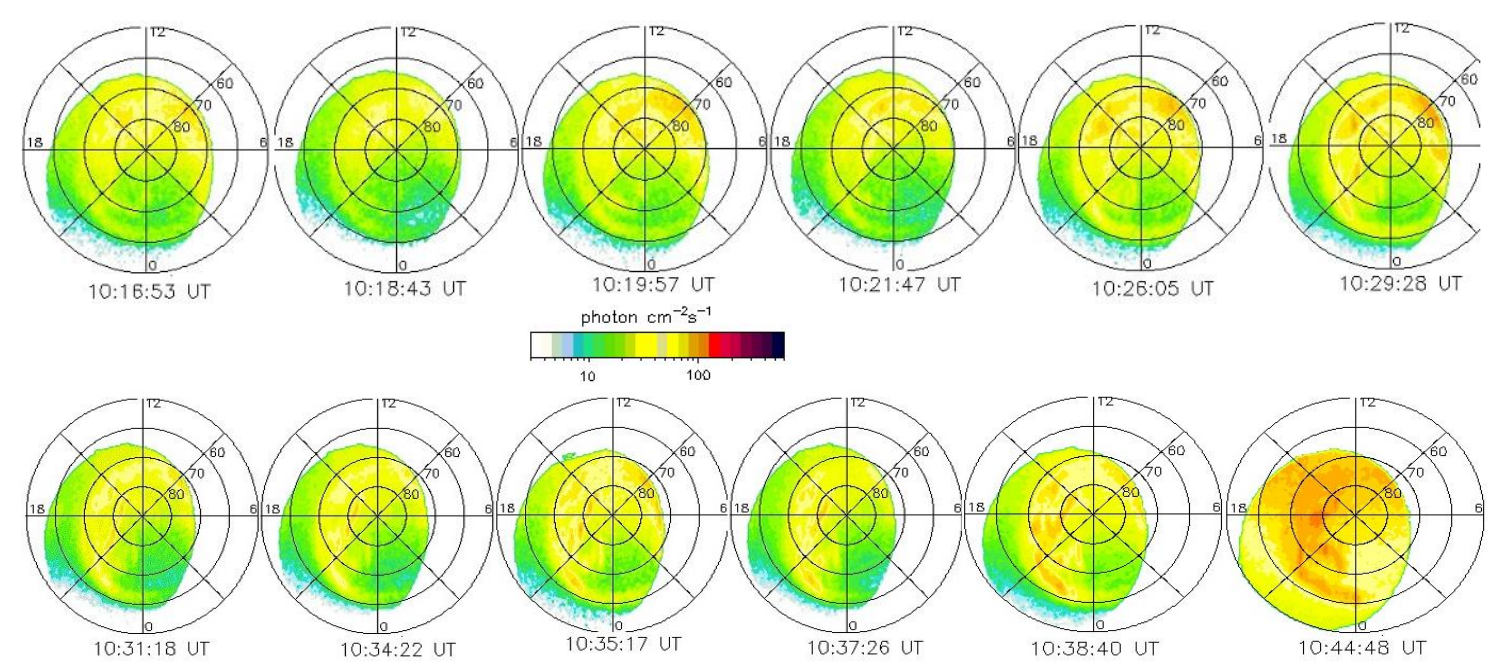

Figure 4. Sequence of auroras during the DS-magnetosphere interaction on June 26, 1998. Images are from the Polar satellite with the LBHL filter
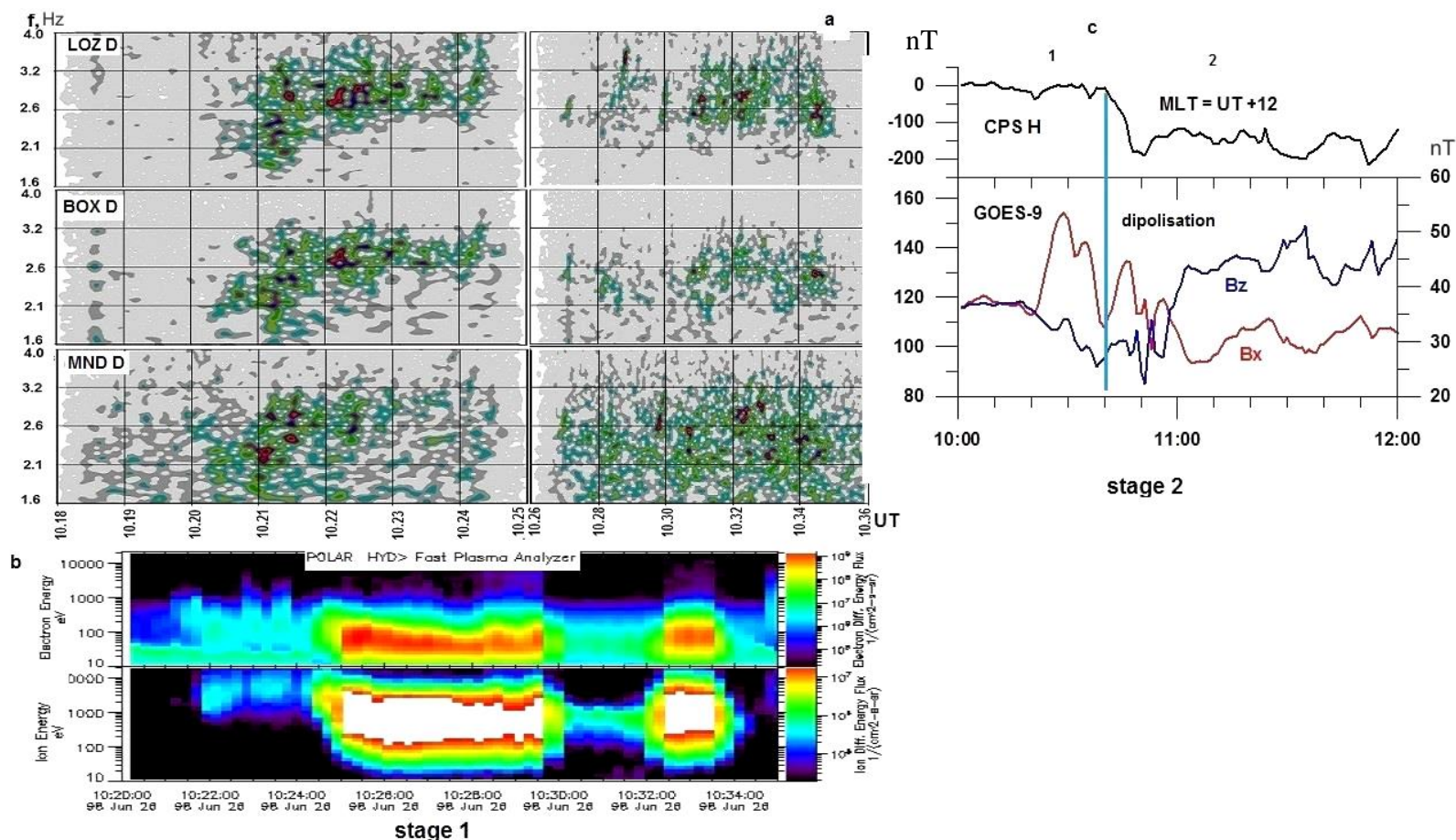

stage 1

Figure 5. Two stages of the DS-magnetosphere interaction: $a-$ stage 1. Oscillations with nonstationary spectrum at the network of dayside observatories, which are generated by particle precipitation from the radiation belt during sharp compression in the noon-side magnetosphere (Lovozero, $\Lambda=35^{\circ} .08, \Phi=67^{\circ} .97$; Borok, $\Lambda=38^{\circ} 33 \Phi=58^{\circ} .03$; Mondy, $\Lambda=104^{\circ} .45 \Phi=$ $52^{\circ} .17$; Cape Schmidt, CPS, $\Lambda=68^{\circ} .92 \Phi=180^{\circ} .52$ ); $b$ - energy distribution of ions and electrons detected by the Polar satellite. Recording time coincides with the DS passage; $a$ - stage 2 . Variation in the $H$ component derived from the pre-midnight observatory data and $B_{x}$ and $B_{y}$ variations detected by the satellite GOES-9 near the midnight sector along the plasma sheet axis

The material presented shows that DS and the magnetosphere at positive $B_{z}$ interact in two stages. At the first one, due to the sharp compression of the magnetosphere (the bow shock shifts by $1.5 R_{\mathrm{e}}$, as derived from OMNI data) particles precipitate from the transition region into the ionosphere of the polar cap at dayside cusp latitudes (Figure 4, the 10:19:57 UT image), which leads to an abrupt increase in auroras. Particle precipitation from the transition layer are also recorded in the magnetosphere in the Polar orbit at a distance of $\sim 7 R_{\mathrm{e}}$ in the dayside sector of $\sim 14$ MLT (Figure 5, $b$ ).
Particle precipitation from the radiation belt leads to an increase in thermal plasma anisotropy and to generation of electromagnetic ion cyclotron (EMIC) waves with nonstationary spectrum (Figure 5,a) [Yakhnin et al., 2019].

The second stage starts after dipolization of the geomagnetic field at the midnight side. As the disturbance develops, plasma moves from noon to midnight (the drift velocity is $6-11 \mathrm{~km} / \mathrm{s}$ [Zhou, Tsurutani, 1999]) and reaches auroral latitudes in the $18-00 \mathrm{hr}$ sector, where the ionospheric current is amplified, which causes the nega- 
tive bay observed at the pre-midnight observatory. After the DS passage, magnetospheric activity returns to the undisturbed level.

\section{The December 09, 1996 diamagnetic structure}

A short substorm differing from that considered in the absence of dayside auroras, and also without growth phase occurred on December 09, 1996 at 21:35-22:30 UT $\left(A E_{\max }=240 \mathrm{nT}, A L_{\max }=-200 \mathrm{nT}\right)$. The mean $B_{z}$ component from 19:00 to 21:30 UT was $1.59 \pm 1.24 \mathrm{nT}$, i.e. $B_{z}$ was predominantly northward for $1.5 \mathrm{hr}$. Tagirov et al. [1998] have shown the substorm began at 21:40 UT against positive, slightly varying IMF $B_{z}$.

The substorm commenced with a sudden brightening of the quiet auroral arc at a latitude of $\sim 72^{\circ}$ in the duskmidnight sector (Figure 6, $a$ ) and with two bursts of Pi2-Pi1B geomagnetic pulsations (Figure 6, b). Sequence of the auroras is shown in Figure $6, c$. We can see the oscillatory nature of the $A E$ rise to a maximum of $249 \mathrm{nT}$ (Figure 3, b). The main difference from the June 26, 1998 event lies in the fact that there were no auroras detected at the noon side because Polar was at the nightside of northern midlatitudes $x \sim(-3 \div-4) R_{\mathrm{e}}, \sim 21 \mathrm{LT}$.

Tagirov et al. [1998] believe that a substorm is triggered by a sharp jump of the dynamic pressure, and the substorm duration is determined from the duration of auroras.Polar UVI images (Figure 2 [Tagirov et al., 1998]) show the brightness of auroras and the size of the convexity continued to increase until 22:09 UT. The convexity almost disappeared by $22: 18$ UT. Referring to Figure $3, b$, the moment of the dynamic pressure jump coincides with the beginning of the DS-magnetosphere interaction.

Thus, duration of the substorm from $21: 40$ to $22: 18$ UT coincides with our definition of DS duration. Figure $3, b$ indicates that a sharp increase in $A E$ starts with a slight delay after the interaction of DS (rectangle) with the magnetopause. Note that $A E$ does not return to the pre-disturbance level since another, more intense substorm begins.

\section{The June 21, 2007 diamagnetic structure}

Keika et al. [2009], using a large amount of satellite and ground-based observations, have examined the June 21, 2007 substorm whose explosive phase began less than two minutes after the interaction between the magnetopause and the SW dynamic pressure jump. Figure 3 , $c$ shows that it is not simply a pressure jump, but the onset of DS such that the anticorrelation between $N$ and $B r=-0.74$.

Just as in the December 09, 1996 substorm, the active phase begins without preliminary energy accumulation in the magnetotail. Figure 4 in [Keika et al., 2009] presents keograms of auroras from the Polar satellite in the Southern Hemisphere, which demonstrate the onset of the substorm in auroras without growth phase.

In addition to data from [Keika et al., 2009], for the June 21, 2007 event in Figure 7 we present images of the south polar ionosphere similar to those shown in Figure 4 of the cited paper. At 12:43 UT, we can see the initial brightening of the quiet arc, and at 12:46:45-
12:47:22 UT a sharp increase occurred in the glow of auroras (breakup) at magnetic latitudes $60^{\circ}-70^{\circ}$ and in the range $21-03$ MLT. The onset of the aurora brightening coincided with the DS-magnetopause interaction and with the sharp increase in $A E$ at 12:46 UT (Figure 3, $c$ ). Also noteworthy is the aurora brightness modulation associated with $N$ and $B$ variations. Variations of the SW and IMF parameters are also reflected in $A E$ and $S Y M H$ variations in Figure 3, $c$.

Thus, a source of the June 21, 2007 substorm is DS. By hypothesis [Keika et al., 2009], development of this substorm is linked to the emergence and propagation of a compression wave into the magnetotail, which, as we have found out, is driven by the DS-magnetopause interaction. According to [Keika et al., 2009], propagation of the compression wave did not cause compression of flanks of the magnetosphere. Therefore, the authors believe that this substorm might have been triggered by the electric field induced by the compression wave, which was directed to the dawnside magnetosphere, i.e. opposite to the convective electric field (aka dawndusk field).

Such an alternative mechanism has been discussed in [Araki, 1994]. Note that the main causes for the convection reduction in the plasma sheet and for the subsequent development of the substorm are usually considered to be either a change in the $B_{z}$ direction from southward to northward or a decrease in $B_{y}$ [Lyons et al., 2003, 2005]. For this event [Keika et al., 2009], it has been shown that there were no such changes in the IMF vector components before the substorm. According to the time analysis carried out by the authors, the compression wave reached the magnetotail after the onset of the substorm. Let us make an additional comment on the sudden pulse that is regarded as a trigger of the substorm [Keika et al., 2009]. Note first that in the catalog [http: //www.obsebre.es/en/rapid] there were no sudden storm commencements SSC and SI recorded that day. Our analysis of data from the International Real-Time Magnetic Observatory Network INTERMAGNET also suggests that at the time of interest it is not SI that is recorded but a global positive disturbance caused by magnetosphere compression and lasting for $\sim 50 \mathrm{~min}$.

Note the behavior of $P C N$ in the three events considered. According to [Troshichev, Sormakov, 2019], the onset of a magnetospheric substorm is always preceded by an increase in the index. The sudden substorm commencement is generally linked to a marked increase in $P C N$ occurring 0-10 min before the commencement. More than $75 \%$ of substorms begin at $P C N=1 \div 2 \mathrm{mV} / \mathrm{m}$. Nonetheless, in our cases an increase in $P C N 20 \mathrm{~min}$ before the onset of the substorm disturbance from $\sim 1$ to $\sim 2 \mathrm{mV} / \mathrm{km}$ was observed only in the June 26, 1998 event. $P C N$ varied at a level of $\sim 0.5 \mathrm{mV} / \mathrm{km}$ on December 09, 1996, and it sharply decreased from $4 \mathrm{mV} / \mathrm{km}$ to 0 on June 21, 2007. Another common pattern of the substorm disturbances considered is a sharp increase in the $S Y M-H$ - index by $10-50 \mathrm{nT}$, coinciding in the rise time and duration with those of DS, which is characteristic of the interaction of the magnetosphere with interplanetary shocks and MHD discontinuities in SW plasma. 

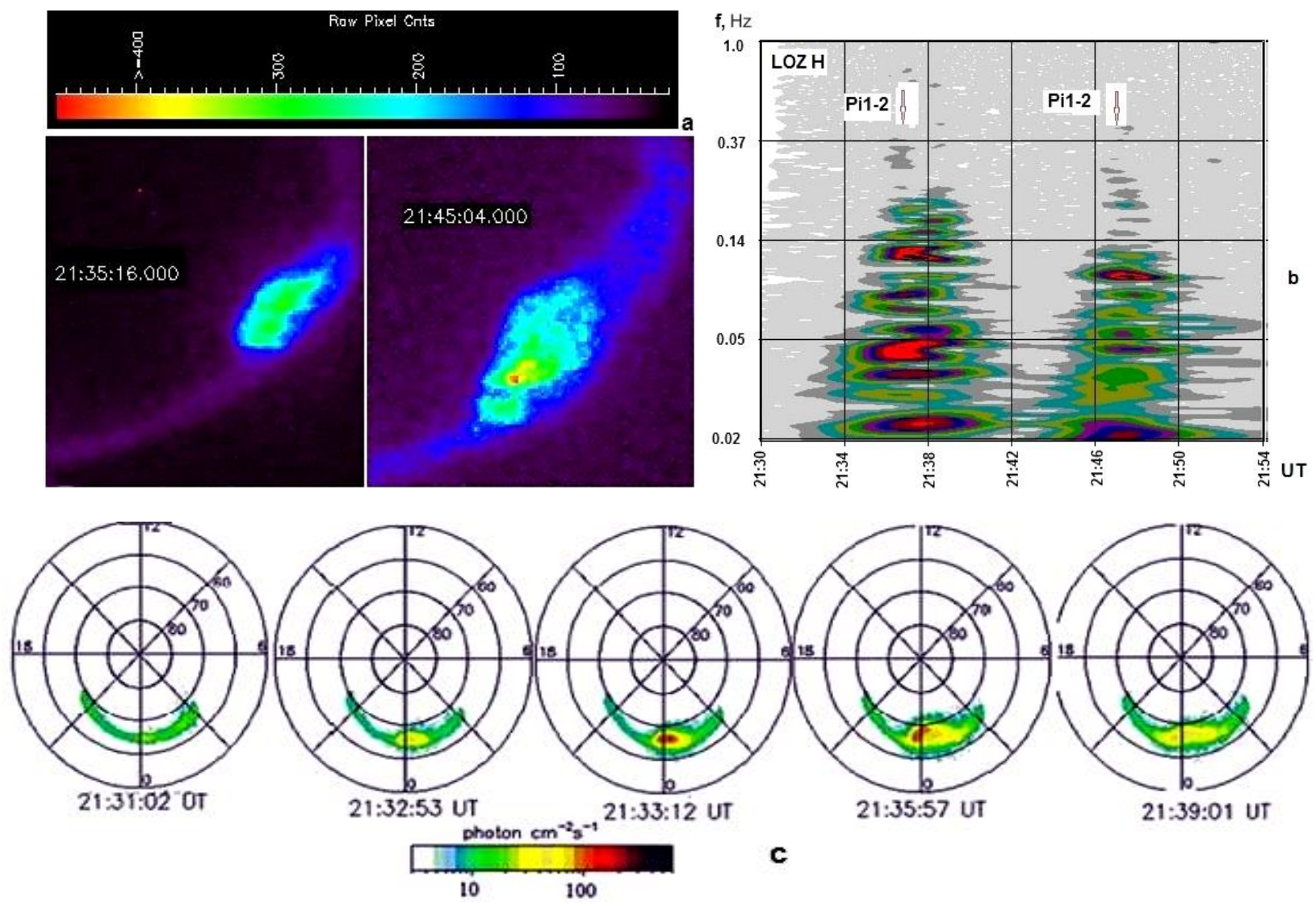

Figure 6. Sequence of auroras during the DS-magnetosphere interaction on December 09, 1996. Images of auroras taken by the Polar satellite with the PO_KO_UVI instrument $(a)$; sonograms of geomagnetic pulsations from the Lovozero observatory (b); images from the Polar satellite with the LBHL filter $(c)$

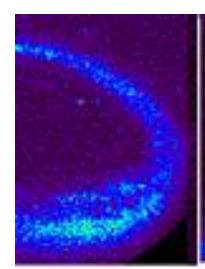

$12: 43$

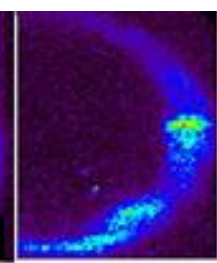

$12: 46: 45$

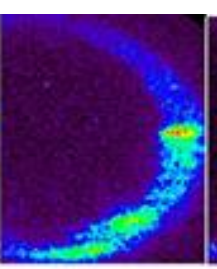

$12: 47: 22$

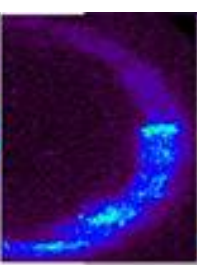

$12: 48: 36$

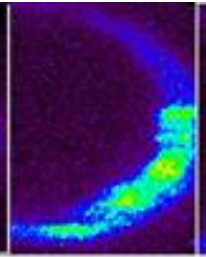

$12: 50: 26$

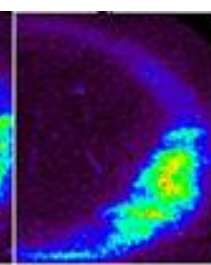

$12: 51: 40$

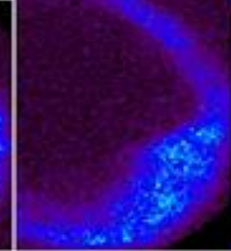

13:10

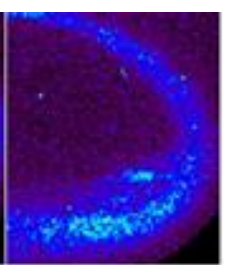

$13: 32: 45$

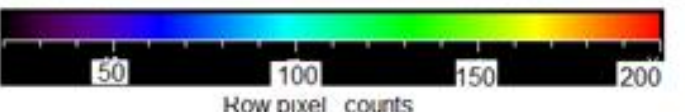

Figure 7. Sequence of the June 21, 2007 substorm in auroras. The aurora images were taken by the Polar satellite with the PO_KO_UVI instrument

We can draw the following general conclusions from the analysis of the DS-magnetosphere interaction at the preceding long-lived northward IMF vertical component and in the cases when during the interaction the component does not change its direction into southward.

1. When DS interacts with the magnetosphere, substorm disturbances of two types are generated. The probable reason for the difference may be the difference between the density jump and the rate of its increase. At a high and sharp density jump, a disturbance begins with midday-side shock auroras generated by precipitation of particles from the transition region and their subsequent drift to the night side, by dipolization of the magnetic field in the nightside magnetosphere, and by onset of a substorm. Typical examples are observed on June 26, 1998 (10:11 UT), August 01, 1998 (16:19 UT), June 15, 2000 (01:02 UT), etc.

2. In the cases when the interaction with DS does not excite shock auroras at the midday side, a substorm begins with generation of a compression wave, its propagation into the magnetotail, and with triggering of a substorm due to the fact that the IMF jump causes the dawn-dusk electric field and the energy input to the magnetosphere to increase.

3. The duration of such isolated substorms approximately coincides with the duration of DS, and the intensity does not exceed $A E \sim 500 \mathrm{nT}$. 


\section{Features of type 2 magnetospheric response to the interaction with DS. Observational results}

Let us assign the responses during which for a long time (more than $1 \mathrm{hr}$ ) the IMF northward vertical component was recorded and the moment when $B_{z}$ changed its direction into southward to $-3 \div-10 \mathrm{nT}$ coincided with the beginning of DS, to type 2 . After sharply deviating to the south, $B_{z}$ smoothly (to $\sim 3 \mathrm{hr}$ ) returns to the positive direction during the substorm (Figure $8, a$ ). The date of this event, February 27, 1998, is taken from [Janzhura et al., 2007]. Such events are also shown in Figure 9, $a-c$.

The duration of the substorm disturbance coincides with the duration of DS. The dynamics of type 2 responses is similar to the dynamics of the classical substorm in the presence of the growth phase, which begins when DS interacts with the magnetosphere and when $B_{z}$ changes direction.

Before turning to the analysis of the magnetospheric response of this type to $\mathrm{DS}$ at $1 \mathrm{AU}$, we use the response as an example to show how to identify the solar source of DS.

Figure $8, b$ illustrates hourly-resolved changes in SW parameters from February 24, 1998 to March 02, 1998, the period includes the time interval of the DS of interest (marked with vertical lines). The fact that this area is connected with the streamer belt is evidenced by the presence of a change in the azimuthal magnetic field by $\sim 180^{\circ}$, from $\sim 90^{\circ}$ to $\sim 270^{\circ}$, in its vicinity, i.e. the IMF sector boundary.

To identify its source on the Sun, we proceed from the following established and experimentally verified assumption [Eselevich et al., 2007]: a source on the solar surface should be located in the vicinity of the intersection point of the streamer belt and the ecliptic. On the synoptic map, to the streamer belt corresponds the neutral line (NL) (thick solid line NL in Figure 8,c) of the global magnetic field, which separates positive (solid curves) and negative (dashed line) field polarities in Figure 8, $c$. We can see that at $t_{0}$ (February 23, 1998, 01:00 UT) the vicinity of the intersection point of NL and the ecliptic (marked with a circle) crosses the central meridian (vertical line). This part of NL is a source of slow SW such that the time of its arrival in Earth's orbit $t_{\text {Earth }}$ can be calculated from the formula [Eselevich et al., 2007]

$$
t_{\text {Earth }} \approx t_{0}+4.6 \cdot 104 / V, \mathrm{hr}
$$

where $V$ is the velocity of the region of slow $\mathrm{SW}$ at 1 AU considered $(\mathrm{km} / \mathrm{s})$.

Referring to Figure $8, b$, in Earth's orbit the velocity of slow SW in DS $V \sim 320 \mathrm{~km} / \mathrm{s}$. Therefore, the transit time according to Formula (1) is $\sim 6$ days, which corresponds to $t_{\text {Earth }} \sim 4$ hrs on February 29, 1998. It up to 1.5 days or $25 \%$ of the transit time corresponds to the position of the IMF sector boundary in Figure $8, b$. This accuracy is acceptable in view of the small inclination of NL, calculated in the potential approximation in Figure $8, c$, to the equator, the more so since in the period from at least February 26, 1998 (00:00 UT) to February 29, 1998 (10:00 UT) there are no other sector boundaries. Figure 8, $c$ shows that the DS with the IMF sector boundary is part of the heliospheric plasma sheet (HPS), which is notable for the high density with $N>10 \pm 2 \mathrm{~cm}^{-3}$ and relatively low $V \sim 320-450 \mathrm{~km} / \mathrm{s}$.

Having identified the solar source of DS, we consider its magnetospheric response. Figure 8, $a$ indicates that, unlike type 1 magnetospheric responses, after preceding prolonged $(1.5 \mathrm{hr})$ northward $B_{z}$ on the DS boundary at 06:25 the IMF vertical component turns southward. This moment coincides with the beginning of DS, which is found from the anticorrelation between $B$ and $N(r=-0.85)$, taken from ACE satellite observations. The time of DS onset is recalculated taking into account the movement of the structure from the satellite.

From the $A E$ variation we can define the magnetospheric response as a substorm from its dynamics close to the classical substorm. Figure 8, $a$ shows the presence of the growth phase lasting for $\sim 1 \mathrm{hr}$. Fluctuations with a period $\sim 5-15 \mathrm{~min}$ are superimposed on $A E$ and $A L$ variations. Such fluctuations are defined as long-period pulsations Pi3 (Ps6) associated with substorms [Nishida, 1980]. The presence of fluctuations with long periods (30-120 $\mathrm{min})$ is also characteristic of sawtooth substorms [Troshichev et al., 2011].

The data presented in Figure 8 shows that the HPS DS energy originating from the streamer belt, when colliding with Earth's magnetosphere, causes a magnetospheric response in the form of an isolated substorm. The substorm duration coincides with the DS duration. Simply put, the energy of the substorm considered depends not only on the energy accumulated in the magnetotail due to reconnection of IMF lines and the geomagnetic field, but also on the input of SW DS kinetic energy to the magnetosphere during the growth phase.

The features of the type 2 magnetospheric response are confirmed in Figure 9. Here, as in the example in Figure 8, the substorm growth phase begins after $B_{z}$ turns to the south and after DS starts to interact with the magnetosphere. Another feature is that onsets of the substorms concur with a decrease in $S Y M H$, i.e. with the amplification of the ring current, which distinguishes this type of response from the type 1 response such that $S Y M H$ sharply increases due to current amplification, induced by magnetosphere compression, at the magnetopause. On the contrary, a sharp decrease in SYMH reflects the amplification of the ring current and the onset of a magnetic storm. The highest negative $S Y M H=-60 \mathrm{nT}$ was observed for the response to DS on December 14, 2015, when the SW density in the structure varied from 20 to $60 \mathrm{~cm}^{-3}$. That day, $A E$ reached $\sim 2000 \mathrm{nT}$ at constant $V_{\mathrm{SW}} \sim 400 \mathrm{~km} / \mathrm{s}$ (Figure 9, $c$ ). Prior to the substorms, $P C N$ did not exceed $0.5 \mathrm{mV} / \mathrm{m}$ and increased to $4 \mathrm{mV} / \mathrm{m}$ synchronously with an increase in $A E$. This periodicity of the $P C N$ variation is not consistent with the results received in [Troshichev et al., 2011], where it has been shown that in $75 \%$ of cases the substorm explosive phase begins at $P C N=1 \div 2 \mathrm{mV} / \mathrm{m}$, regardless of the growth phase duration and the substorm type.

Conclusions from the analysis of the type 2 response to the DS-magnetosphere interaction

The main feature of the type 2 magnetospheric response is that the moment of the DS-magnetosphere interaction concurs with the moment of the change in the IMF vertical component polarity sign. The second feature lies in the presence of the growth phase from the time of the 

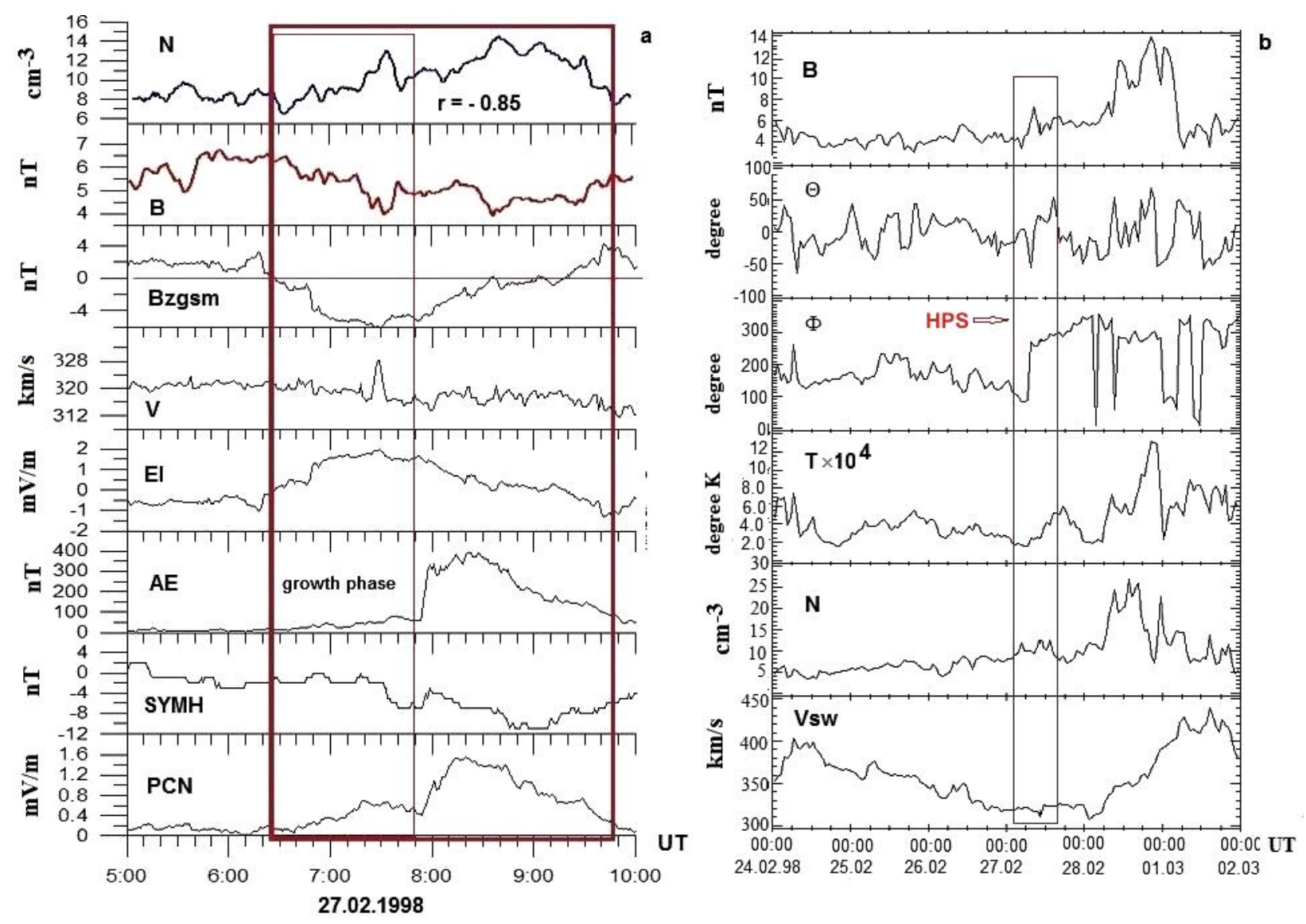

C

Source Surface Fteld

$0 .+1.2 .5 .10 .20$ MicroTesls

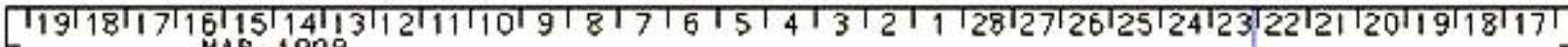

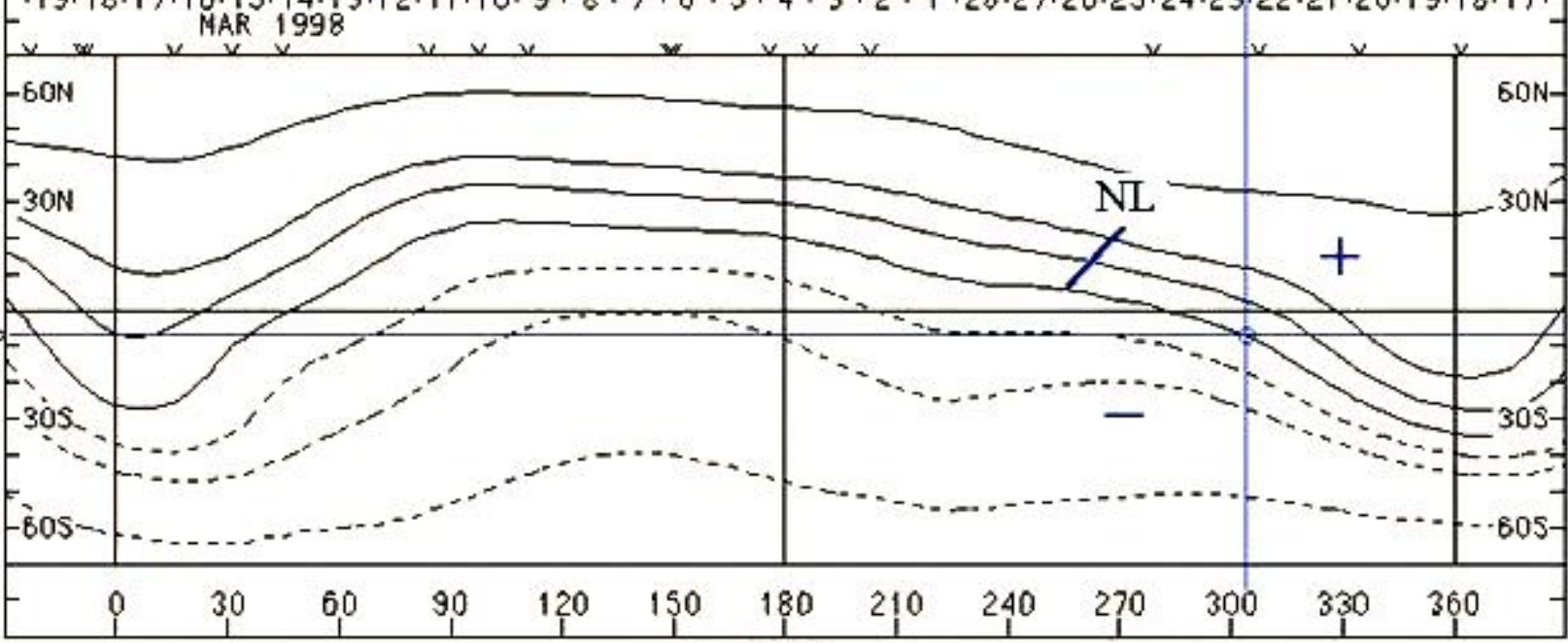
1933

Figure 8. Type 2 magnetospheric response (a) to the interaction with DS of slow SW on February 27, 1998. The thick rectangle marks the entire DS; and the thin rectangle, part of DS that coincides with the duration of the growth phase of an isolated substorm. From top to bottom: IMF modulus $B$, SW plasma density $N$, IMF $B_{z}\left(B_{z \mathrm{GSM}}\right), V_{\mathrm{SW}}$ at $1 \mathrm{AU}, A E, S Y M H$, and $P C N$ indices. DS are indicated by rectangles with the correlation coefficient inside. The growth phase is the preliminary phase. A region of the streamer belt $(b)$ in Earth's orbit or the heliospheric plasma sheet HPS (marked with a rectangle). From top to bottom: IMF modulus, latitude angle $\Theta$, IMF azimuth angle $\Phi$, SW plasma temperature, SW plasma density, SW velocity. Derived from OMNI data [http://cdaweb.gsfc.nasa.gov/cgi-bin/eval2.cgi]; synoptic map (c) of 1933 Carrington rotation for the solar magnetic field, calculated in a potential approximation [http://wso.stanford.edu/]: solid curves indicate positive polarity, the dotted line shows negative polarity, NL is the neutral line of the global solar magnetic field; the circle marks the vicinity of the point of intersection of NL with the ecliptic 

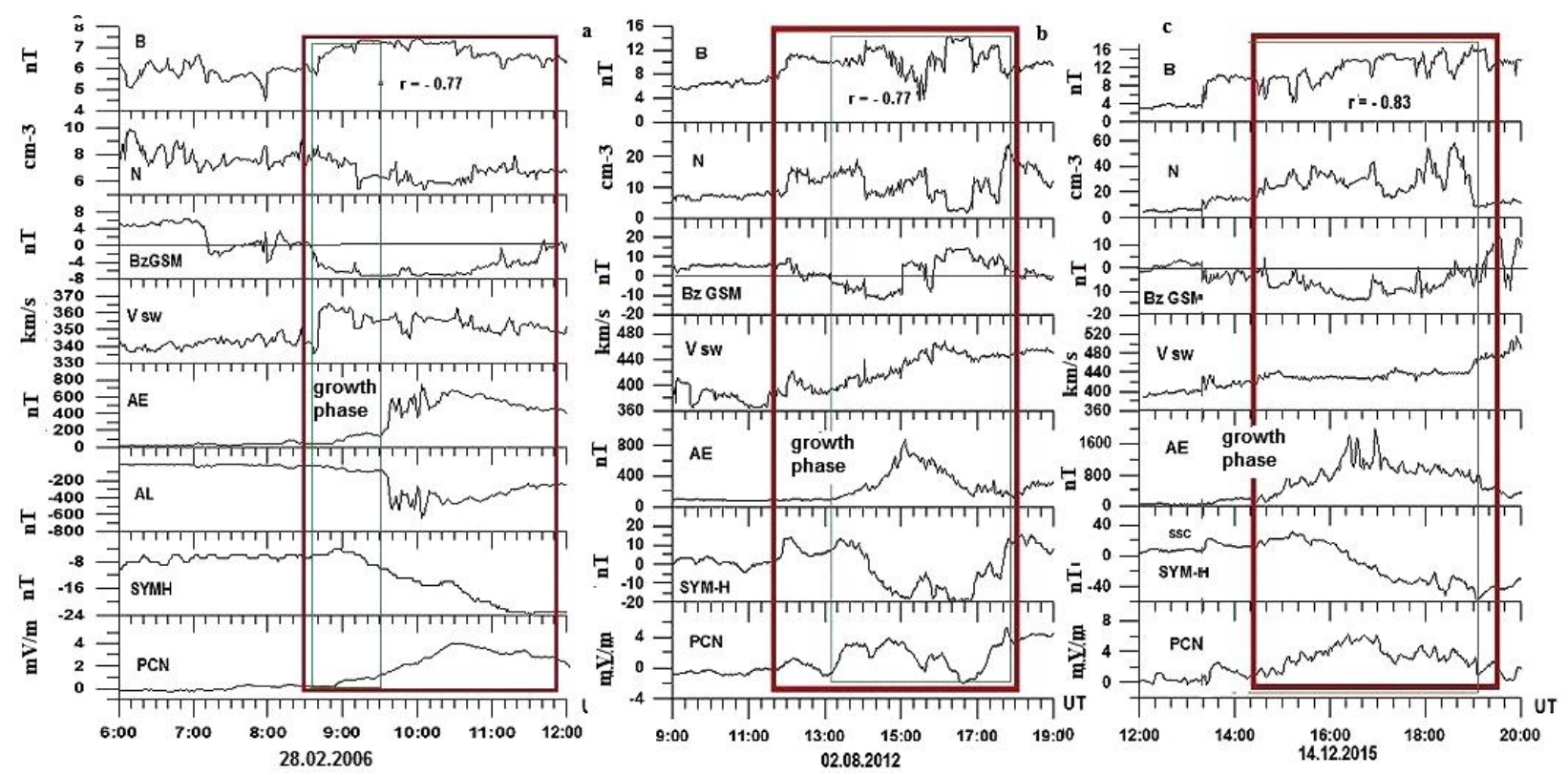

Figure 9. Examples of the type 2 magnetospheric response for February 28, 2006, August 02, 2012, December 04, 2015. From top to bottom: IMF modulus $B$, SW plasma density $N$, IMF $B_{z}$ component $\left(B_{z \mathrm{GSM}}\right)$, SW velocity at $1 \mathrm{AU}\left(V_{\mathrm{sw}}\right), A E, \mathrm{SYMH}$, and PCN indices. DS are indicated by rectangles with the correlation coefficient inside. The growth phase is the preliminary phase. According to OMNI data [http://cdaweb.gsfc.nasa.gov/cgi-bin/eval2.cgi]

polarity reversal to the onset of the substorm disturbance. The type 2 magnetospheric response to the interaction with DS is the closest to the concept of substorm. It is important to emphasize that in the cases considered the substorm energy is provided by two sources - the kinetic energy transported by DS and the energy stored in the magnetotail due to the classical mechanism of reconnection of the geomagnetic and interplanetary fields.

Features of type 3 magnetospheric response to the interaction with DS. Observational results

The main feature of type 3 responses is a large negative value $(-10 \div 0 \mathrm{nT})$ of $B_{z}$ for one hour before the interaction with DS.

Referring to Figure $10, a-c$, the arrival of DS in Earth against preceding large negative $B_{z}$ causes a sharp increase in magnetic activity throughout the magnetosphere. The ring current is amplified in the auroral zone and in the polar cap, which manifests itself as a sharp increase in $S Y M H, A E$, and $P C N$ coinciding with the moment of the DS-magnetosphere interaction. The duration of the substorm disturbances is the same as that of DS.

The most striking case is the December 23, 2002 event during which the increase in auroral activity was as large as $1200 \mathrm{nT}$ (Figure 10,c). In this case, spatial and temporal scales of DS in SW and DS in the transition layer proved to be close, which means penetration of the DS into the transition layer through near-Earth bow shock [Karlson et al., 2015]. The sharp increase in the indices coinciding with the DS duration is observed for the April 21,1997 and April 05, 2006 events in Figure 10, $a-c$, as well as for the December 20, 2011 and November 27, 2010 events, which we omit here, but have examined. All the type 3 responses exhibit the oscillatory nature of $A E$ variations with periods of 20 to $60 \mathrm{~min}$. This allows us to classify substorm disturbances as sawtooth. In all the cases considered, the DS-magnetosphere interaction occurs against intense preceding magnetic disturbance of the magnetosphere, therefore we cannot identify the growth phase of the disturbance and should reckon its beginning from the previous high level of activity. Also noteworthy is high $P C N(>2.5 \mathrm{mV} / \mathrm{km})$ in all the events under study.

Conclusions drawn from the analysis of type 3 response to the DS-magnetosphere interaction

The main feature of the type 3 response to the DSmagnetosphere interaction is a sharp increase in the magnetospheric disturbance level and amplification of current systems, measured by SYMH, $A E$, and PCN. Another feature is the presence of long-period $(8-25 \mathrm{~min})$ SYMH and $A E$ fluctuations, which allows us to assign responses of this type to sawtooth substorms. The duration of the magnetospheric response is equal to the duration of the DS kinetic energy input to the magnetosphere.

\section{DISCUSSION}

The observations we have made suggest that the substorm energy is determined not only by the traditional mechanism of reconnection of geomagnetic and interplanetary field lines, but also by the input of the SW kinetic energy transferred by diamagnetic structures. The transfer mechanism depends on the direction of the IMF vertical component. In the case of northward component that precedes the interaction with DS and does not change direction after the interaction, there are two types of substorm disturbances. In the first one, the magnetosphere compresses and the solar wind plasma flows to the dayside cusp. As a result, in the dayside magnetosphere there are shock auroras, precipitation of particles from radiation belts, and excitation of Hertz range geomagnetic pulsations with nonstationary dynamic 

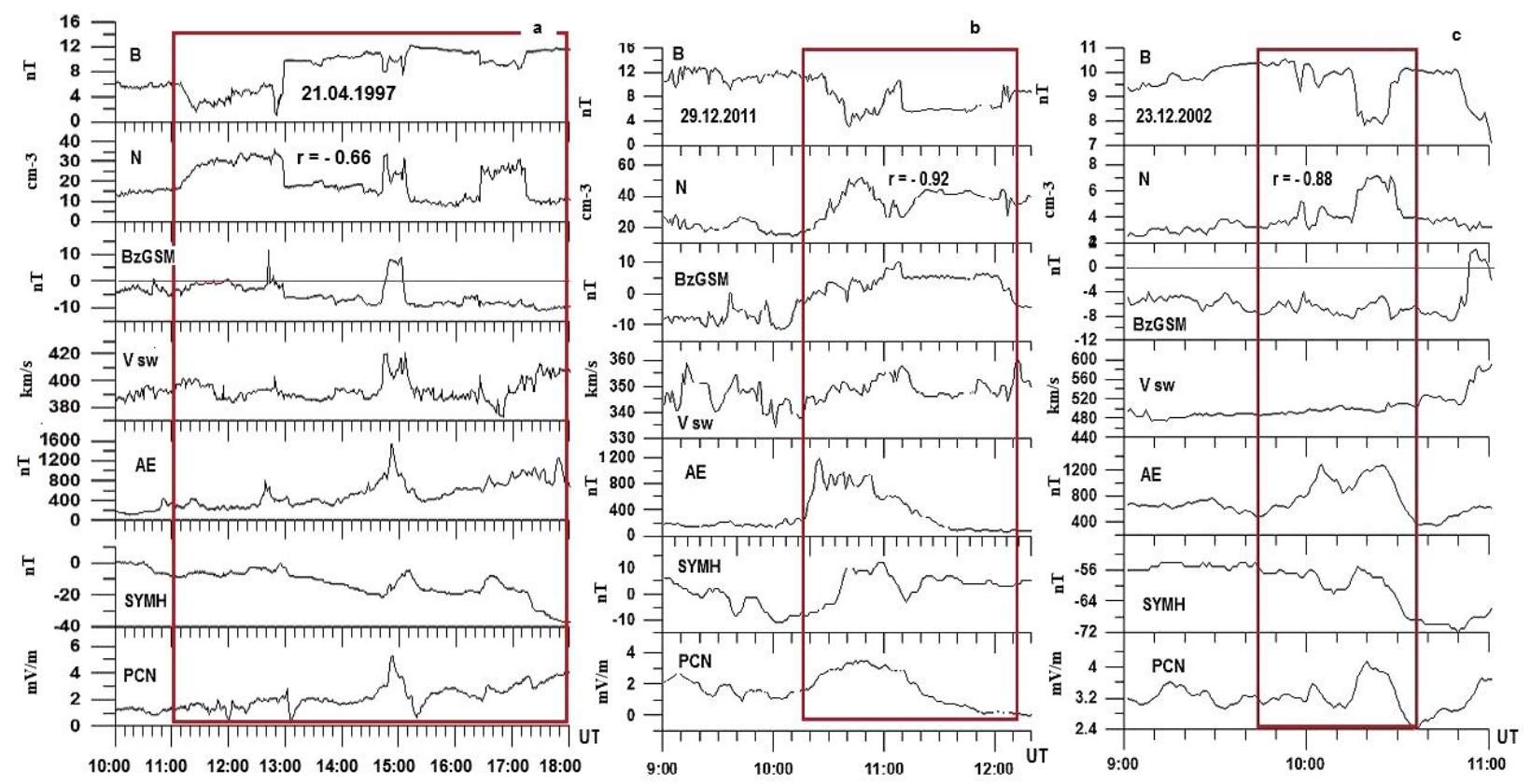

Figure 10. Three examples of the type 3 response to the DS-magnetosphere interaction on April 21, 1997, April 05, 2006, and December 23, 2002. From top to bottom: time dependence of the IMF modulus (B), SW plasma density $(N)$, IMF $B_{z}\left(B_{z \mathrm{GSM}}\right)$, $V_{\mathrm{SW}}$ at $1 \mathrm{AU}, A E, S Y M H$, and $P C N$. DS are indicated by rectangles with the correlation coefficient inside. According to OMNI data [http://cdaweb.gsfc.nasa.gov/cgi-bin/eval2.cgi]

spectrum. As the plasma drifts to the night side and due to dipolization of magnetic field lines, plasma sheet particles precipitate from the magnetotail, and westward electrojet currents increase sharply. Auroras spread across the auroral oval.

Substorm disturbance of the second type at positive $B_{z}$ are associated with the generation of a compression wave, its propagation to the magnetotail, and substorm triggering. It is possible that under such conditions two mechanisms of energy pumping into the magnetosphere may be effective: fast that is linked to pressure, and slow associated with electromagnetic induction due to the impact of a positive electric field induced in the interplanetary (IP) medium.

This idea is consistent with the conclusions drawn in [Parkhomov et al., 2011] that the magnetosphere compression increases the energy of plasma sheet particles and amplifies global current systems. The IMF jump causes the dawn-dusk electric field and the energy input into the magnetosphere to increase. The magnetosphere compression leads to an increase in the pitchangle diffusion of plasma sheet electrons and in aurora activity.

Type 2 substorm disturbances are similar to the classical substorm in morphological characteristics and evolution dynamics. In this case, simultaneously with the DS-magnetosphere interaction, the IMF vertical component, which for more than $1 \mathrm{hr}$ before the interaction was northward, becomes southward. Energy accumulation in the magnetotail comes from two sources of magnetic energy - transfer of the magnetic energy of reconnection and the part of SW kinetic energy that enters the magnetosphere. In this regard, refer to [Lundin et al., 2003; Dmitriev, Suvorova, 2015], which show the possibility of pulsed SW plasma flow through the dayside magnetopause via jets. According to [Dmitriev, Suvorova, 2015], the mean plasma stream in penetrating jets is $\sim 3 \cdot 10^{8} \mathrm{~cm}^{-2} \mathrm{~s}^{-1}$, which is 1.5 times greater than the SW stream.

An example of observation of the type 2 magnetospheric response during which there was a large-scale jet [Dmitriev, Suvorova, 2015] penetrating from the magnetosheath into the magnetosphere, when it interacts with DS, is given in Figure $11, a-c$. The DSmagnetosphere interaction begins at 15:20 UT. That time there are SW density, IMF modulus, and vertical component jumps ( $B_{z}$ varies from -4 to $\left.+2 \mathrm{nT}\right)$. From $16: 30$ to $19: 30$ UT, DS $(r=-0.75)$ is observed. At 16:53 $\mathrm{UT}, B_{z}$ jumps sharply to the south, which coincides with the beginning of the recording of the jet. THEMIS-C on June 3, 2007 at 16:53-17:20 UT observed in the transition layer the energy flux density that appeared to be higher than that of incoming SW, which was detected by the interplanetary monitor ACE, such that their ratio $R_{\mathrm{tot}}>1$. In Figure 11, $a-c$, this interval is denoted by 1 . At the same time, THEMIS-A detected penetration of transition layer plasma with energies of about hundreds of electron volts into the magnetosphere. At 17:1117:16 UT, THEMIS-A watched the very jet that substantially disturbed the stationary geomagnetic field. Thus, on June 3, 2007 at 16:53-17:20 UT a large-scale jet was generated, whose interaction with the magnetopause led to penetration of transition layer plasma into the dayside magnetosphere. We can assume that penetration of the jet into the magnetosphere simultaneously with the turn of $B_{z}$ to the south triggered the substorm. 


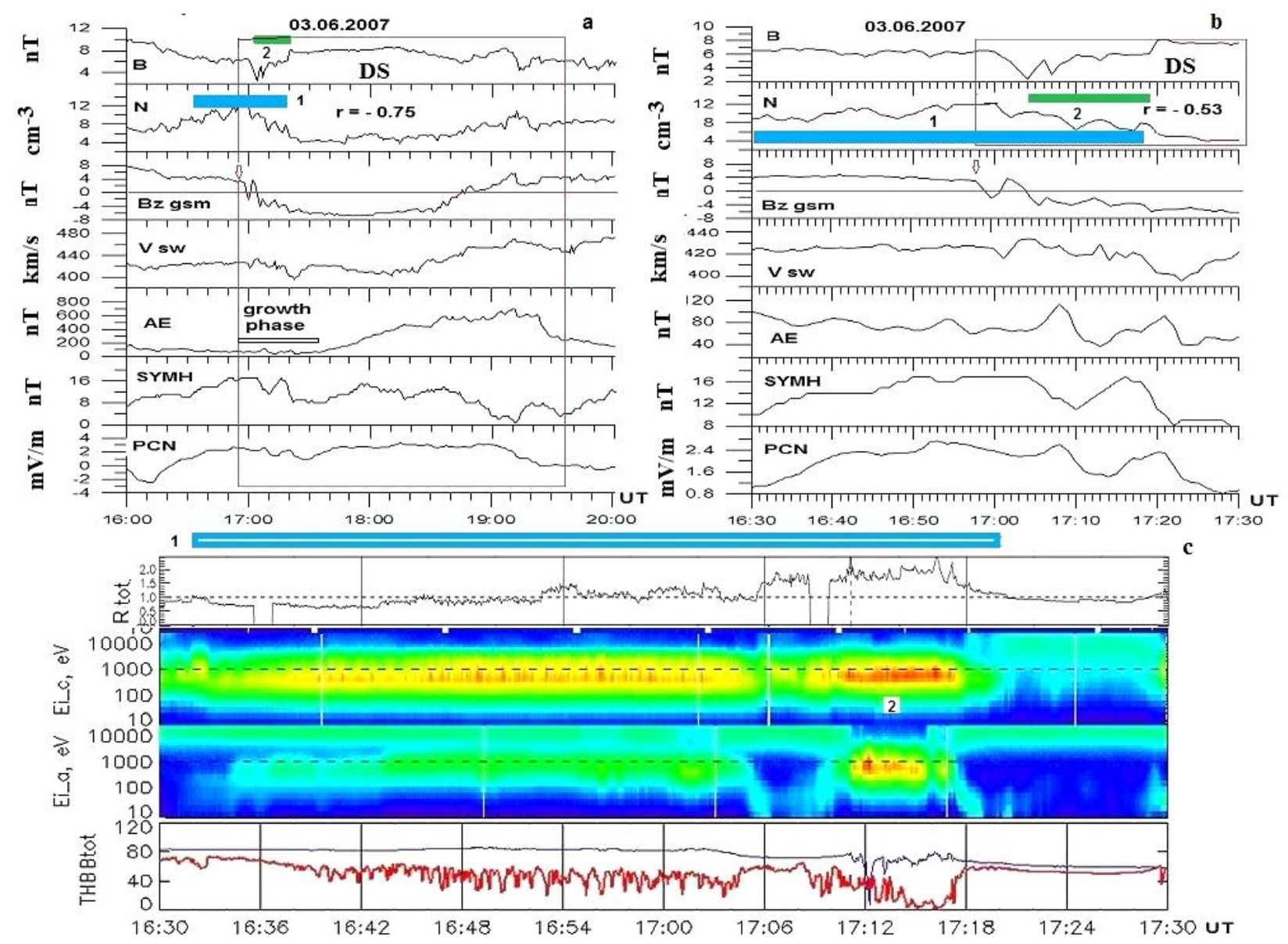

Figure 11. Type 2 magnetospheric response to the interaction with DS in the course of which THEMIS satellites on June 3, 2007 at 16:32-17:20 UT recorded plasma penetration from the transition layer into the magnetosphere. Numeral 2 denotes the entire jet; and numeral 1, its most intense part. From top to bottom $(a)$ : IMF modulus $B$, SW plasma density $N$, IMF $B_{z}\left(B_{z G S M}\right)$, $V_{\mathrm{SW}}$ at $1 \mathrm{AU}, A E, S Y M H, \mathrm{PCN}$. DS is denoted by a rectangle with the correlation coefficient inside. According to OMNI data [http://cdaweb.gsfc.nasa.gov/cgi-bin/eval2.cgi]. A fragment of Figure 11, $a$ corresponding to the interval of jet observation (b). From top to bottom $(c)$ : ratio of the total energy flux density $R_{\text {tot }}$ in the transition layer and in SW as derived from THEMIS-C and ACE data respectively; spectrogram of ions according to THEMIS-C data; magnetic field intensity derived from THEMIS-C (red curve) and THEMIS-A (blue curve) data

Type 3 magnetospheric responses occur when DS propagates against large values of the southward vertical component. In this case, intense substorms $(A E$ $2000 \mathrm{nT}$ ) occur which are accompanied by 20-60 min current fluctuations, which is typical of sawtooth substorms [Troshichev et al., 2011] at a constant slow SW velocity.

We express our sincere gratitude to NASA CDAWEB for providing OMNI data from ACE Wind, Polar, GOES-8, GOES-9, THEMIS, INTERBALL-1. We thank leaders, developers of the instruments and leaders of the experiments, conducted with these satellites, for the possibility of using the data. The work of Parkhomov V.A. and Vedernikova T.I. was performed under the dedicated complex program of scientific research and innovative developments of the Federal State Budgetary Educational Institution of Higher Education «BSU» for 2015-2020 «System Analysis and Data Processing Methods in Space Research». The work of Parkhomov V.A. was supported by RFBR grant under research project No. 18-55-52006 MNT_a. Eselevich V.G. and Eselevich M.G. carried out their work as part of State task for 2018 No. 007-00163-18-00 from Janu- ary 12, 2018. The work of Suvorova A.V. was supported by MOST grants Nos. 07-2811-M-008-1514 and 106-2111-M-008-030-MY3 from the National Central University in Taiwan. The work of Dmitriev A.V. was partially supported by MOST grants Nos.107-2111-M008-011 and 107-2923-M-008-001-MY3/18-55-52006 MNT_a.

\section{REFERENCES}

Akasofu S.-I. The development of the auroral substorm. Planetary Space Sci, 1964, vol. 12, pp. 273.

Akasofu S.-I. The solar wind-magnetosphere energy coupling and magnetospheric disturbances. Planetary Space Sci. 1980, vol. 28, iss. 5, pp. 495-509. DOI: 10.1016/00320633(80)90031-8.

Araki T. A physical model of the geomagnetic sudden commencement. Solar Wind Sources of Magnetospheric ULF Waves. 1994, vol. 81, pp. 183-200. AGU, Washington.

Clauer C., Cai X., Welling D., DeJong A., Henderson M. Characterizing the 18 April 2002 storm-time sawtooth events using ground magnetic data. J. Geophys. Res. 2006, vol. 111, A04S90. DOI: 10.1029/2005JA011099.

Dmitriev A.V., Suvorova A.V. Large-scale jets in the magnetosheath and plasma penetration across the magneto- 
pause: THEMIS observations. J. Geophys. Res.: Space Phys. 2015, vol. 120, iss. 6. DOI: 10.1002/2014JA020953.

Eselevich M.V., Eselevich V.G. Fractal structure of the heliospheric plasma sheet at the Earth's orbit. Geomagnetizm $i$ aeronomiya [Geomagnetism and Aeronomy]. 2005, vol. 45, no. 3, pp. 347-358. (In Russian).

Eselevich M.V., Eselevich V.G., Fujiki K. Streamer belt and chains as the main sources of quasi-stationary slow solar wind. Solar Phys. 2007, vol. 240, pp. 135.

Eselevich V.G. Diamagnetic structures as a basis of quasistationary slow solar wind. Solar-Terrestrial Physics. 2019, vol. 5, no. 3, pp. 29-41. DOI: 10.12737/stp-53201904.

Huang, C.-S., G. D. Reeves, J. E. Borovsky, R. M. Skoug, Z. Y. Pu, and G. Le. Periodic magnetospheric substorms and their relationship with solar wind variations, J. Geophys. Res., 2003, 108(A6), 1255, doi:10.1029/2002JA009704

Janzhura A., Troshichev O., Stauning P. Unified PC indices: Relation to isolat-ed magnetic substorms. J. Geophys. Res. 2007, vol. 112, iss. A9, citeID A09207. DOI: 10.1029/2006JA012132.

Karlsson T., Kullen A., Liljeblad E., et al. On the origin of magnetosheath plasmoids and their relation to magnetosheath jets. J. Geophys. Res.: Space Phys. 2015, vol. 120, iss. 9, pp. 7390-7403. DOI: 10.1002/2015JA021487.

Keika K.R., Nakamura W., Baumjohann W., Angelopoulos V. Substorm expansion triggered by a sudden impulse front propagating from the dayside magnetopause. J. Geophys. Res. Atmosph. June 2009, 114(6) DOI: 10.1029/ 2008JA013445.

Lundin R., J.-A. Sauvaud, H. R`eme. Evidence for impulsive solar wind plasma penetration through the dayside magnetopause. Annales Geophysicae. 2003, vol. 21, pp. 457-472.

Lyons L.R., Liu S., Ruohoniemi J.M., Solovyev S.I., Samson J.C. Observations of dayside convection reduction leading to substorm onset. J. Geophys. Res.: Space Phys. 2003, vol. 108, iss. A3, pp. 1119. DOI: 10.1029/2002JA009670.

Lyons L.R., Lee D.-Y., Wang C.-P., Mende S.B. Global auroral responses to abrupt solar changes: Dynamic pressure, substorms and null events. J. Geophys. Res.: Space Phys. 2005, vol. 110, iss. A08208. DOI: 10.1029/2005JA011089.

McPherron R.L., Weygand J.M., Tung-Shin Hsu. Response of the Earth's magnetosphere to changes in the solar wind. $J$. Atmosph. Solar-Terr. Phys. 2008, vol. 70, no. 2, pp. 303-315. DOI: 10.1016/j.jastp.2007.08.040.

Nishida A. Geomagnitnyi diagnoz magnitosfery [Geomagnetic Diagnosis of the Magnetosphere]. Moscow, Mir, 1980, 222 p. (In Russian).

O’Brien T.P., McPherron R.L. Seasonal and diurnal variation of Dst dynamics. J. Geophys. Res. 2002, vol. 107, no. A11. DOI: 10.1029/2002JA009435.

Parkhomov V.A., Borodkova N.L., Dmitriev A.V., Klimov P.M., Rakhmatulin R.A. The role of solar wind pressure jumps in processes of initiation of magnetospheric storm and its controlling. Solar-Terrestrial Physics. 2011, vol. 18 , no. 3, pp. 109-122. (In Russian).

Parkhomov V.A., Riazantseva M.O., Zastenker G.N. Local Amplification of Auroral Electrojet as a Response to a Sharp Solar Wind Pressure Pulse. Planetary Space Sci. 2005, vol. 53, iss. 1-3, pp. 265-274.

Parkhomov V.A., Borodkova N.L., Eselevich V.G., Eselevich M.V., Dmitriev A.V., Chilikin V.E. Solar wind diamagnetic structures as a source of substorm-like disturbances. J. Atmosph. Solar-Terr. Phys. 2018, vol. 181, part A, pp. 55-67. DOI https://doi.org/10.1016/j.jastp.2018.10.010.

Parkhomov V.A., Eselevich V.G., Eselevich M.V., Dmitriev A.V., Vedernikova T.I. Diamagnetic plasmoids as part of diamagnetic structures of the slow solar wind and their impact on Earth's magnetosphere. Solar-Terrestrial Physics.
2019, vol. 5, no 4, pp. 34-45. DOI: 10.12737/stp-54201905.

Spann J.F., Brittnacher M., Elsen R., Germany G.A., Parks G.K. Initial response and complex polar cap structures of the aurora in response to the January 10, 1997 magnetic cloud. Geophys. Res. Lett. 1998, vol. 25, no.14, pp. $2577-$ 2580 .

Tagirov V.R., Arinin V.A., Meng C.I., et al. Comparison of two substorm onsets on the basis of coordinated groundsatellite observations. International Conference on Substorms-4. Japan, March 9-13, 1998. P. 339-342. Terra Scientific Publishing Company, Tokyo, Japan, 1998.

Troshichev O.A., Sormakov D.A. PC index as a proxy of the solar wind energy that entered into the magnetosphere. Problemy Arktiki $i$ Antarktiki [Arctic and Antarctic Res.]. 2019, vol. 65, no 3. DOI: 10.30758/0555-2648-2019-65-3275-299.

Troshichev O.A., Stauning P., Liou K., Reeves G. Sawtooth substorms: Inconsistency of repetitive bay-like magnetic disturbances with behavior of aurora. Adv. Space Res. 2011, vol. 47, pp. 702-709.

Troshichev O., Janzhura A., Stauning P. Unified PCN and PCS indices: Method of calculation, physical sense and dependence on the IMF azimuthal and northward components // J. Geophys. Res. 2006. V. 111, N A05208. DOI: 10.1029/2009JA014937.

Vorobjev V.G., Antonova E.E., Yagodkina O.I. How the intensity of isolated substorms is controlled by the solar wind parameters. Earth, Planets and Space. 2018a, vol. 70:148. DOI: 10.1186/s40623-018-0922-5.

Vorobjev V.G., Antonova E.E., Yagodkina O.I.,Zverev V.L. Influence of solar wind plasma parameters on the intensity of isolated magnetospheric substorms. Geomagnetism and Aeronomy. 2018b, vol. 58, no. 3, pp. 295-306. DOI: 10.1134/ S0016793218030155.

Yakhnin A.G., Titova E.E., Demekhov A.G., Yakhnina A.T., Popova T.A., Lyubchich A.A., et al. Simultaneous observations of electromagnetic ion cyclotron (EMIC) and ELF/ULF waves and precipitation of energetic particles during multiple compressions of the magnetosphere. Geomagneizm $i$ aeronomiya [Geomagneism and Aeronomy]. 2019, vol. 59, no 6, pp. 714-726. DOI: 10.1134/S0016794019060142. (In Russian).

Zhou X., Tsurutani B.T. Rapid intensification and propagation of the dayside aurora: Large scale interplanetary pressure pulses (fast shocks). Geophys. Res. Lett. 1999, vol. 26, iss 8, pp. 1097-1100. DOI: 0.1029/1999GL900173.

URL: http://pgia.ru/lang/en/data (accessed May 20, 2020).

URL: http://www.obsebre.es/en/rapid (accessed May 20, 2020).

URL: http://spaceweather.ru/ru/node/32 (accessed May 20, 2020).

URL: https://cdaweb.sci.gsfc.nasa.gov/cdaweb/istp_public/ (accessed May 20, 2020).

URL: http://pgia.ru/content/site/pages/PGI-DATA/Listsubstorms_rus.pdf (accessed May 20, 2020).

URL: http://cdaweb.gsfc.nasa.gov/cgi-bin/eval2.cgi (accessed May 20, 2020).

URL: http://wso.stanford.edu/ (accessed May 20, 2020).

URL: ttps://cdaweb.sci.gsfc.nasa.gov/cdaweb/istp_public/ (accessed May 20, 2020).

How to cite this article

Parkhomov V.A., Eselevich V.G., Eselevich M.V., Dmitriev A.V., Suvorova A.V., Vedernikova T.I. Classification of magnetospheric responses to interaction with diamagnetic structures of slow solar wind. Solar-Terrestrial Physics. 2020. Vol. 6. Iss. 4. P. 24-36. DOI: $10.12737 /$ stp-64202004. 